\title{
Numerical Study on Nonlinear Semiactive Control of Steel-Concrete Hybrid Structures Using MR Dampers
}

\author{
Long-He Xu, ${ }^{1}$ Zhong-Xian $\mathrm{Li}^{2}{ }^{2}$ and Yang $\mathrm{Lv}^{2}$ \\ ${ }^{1}$ School of Civil Engineering, Beijing Jiaotong University, Beijing 100044, China \\ ${ }^{2}$ School of Civil Engineering, Tianjin University, Tianjin 300072, China \\ Correspondence should be addressed to Long-He Xu; lhxu@bjtu.edu.cn
}

Received 28 May 2013; Accepted 19 June 2013

Academic Editor: Gang Li

Copyright (c) 2013 Long-He Xu et al. This is an open access article distributed under the Creative Commons Attribution License, which permits unrestricted use, distribution, and reproduction in any medium, provided the original work is properly cited.

\begin{abstract}
Controlling the damage process, avoiding the global collapse, and increasing the seismic safety of the super high-rise building structures are of great significance to the casualties' reduction and seismic losses mitigation. In this paper, a semiactive control platform based on magnetorheological (MR) dampers comprising the Bouc-Wen model, the semi-active control law, and the shear wall damage criteria and steel damage material model is developed in LS-DYNA program, based on the data transferring between the main program and the control platform; it can realize the purpose of integrated modeling, analysis, and design of the nonlinear semi-active control system. The nonlinear seismic control effectiveness is verified by the numerical example of a 15 -story steelconcrete hybrid structure; the results indicate that the control platform and the numerical method are stable and fast, the relative displacement, shear force, and damage of the steel-concrete structure are largely reduced using the optimal designed MR dampers, and the deformations and shear forces of the concrete tube and frame are better consorted by the control devices.
\end{abstract}

\section{Introduction}

Structural control has been proved to be an effective technique to improve the resistance performance of structures excited by both earthquakes and wind through energy dissipation by supplemental devices. In the last several decades, semiactive control methods, for the reliability, adaptability, low power input, controllability, and rapid response capability, have been widely studied, and many control algorithms using MR dampers [1] have been proposed for civil engineering applications and have built a self-contained theory system in the field of the linear system. To consider the nonlinear behaviors of the practical structures, the focus of study has been transferred to the robustness and feasibility of nonlinear control system, and the third generation benchmark model [2] considering the nonlinear property of material was proposed and had made some achievements [3-5]. Lee et al. [6] conducted a numerical study to evaluate the performance of an MR damper for a SDOF structure considering the soilstructure interaction effects, and Li and Wang [7] conducted an experimental investigation to demonstrate the feasibility and capability of MR dampers for seismic control of nonlinear civil structure considering soil-structure interaction effects. Carrion et al. [8] presented an approach for realtime hybrid simulation in which compensation for actuator dynamics is implemented using a model-based feedback compensator. Christenson et al. [9] studied the real-time hybrid simulation experimental setup for multiple large-scale MR dampers and demonstrated the feasibility in a realtime hybrid test. Park et al. [10] presented a quantitative evaluation of the seismic performance of a building structure installed with an MR damper using real-time hybrid testing method. However, most of the studies focus on steel frame structures, and most control algorithms are suitable to the linear structural control under small or medium earthquake motions. In this paper, a semiactive control platform based on MR dampers is developed in LS-DYNA program, and it can realize the purpose of integrated modeling, analysis, and design of the nonlinear semiactive control system. The steel damage model, damage criteria for the concrete shear wall, and the optimal designed control force of MR dampers are also developed. A 15-story steel-concrete hybrid structure 
is analyzed and compared to verify the nonlinear damage control performance on the control platform.

\section{Nonlinear Semiactive Control Formulation}

2.1. Semiactive Control Platform. The semiactive control system consists of the transducers, controller, and actuators. The transducers gather the structural responses and feedback to the controller, the feedbacks and states of MR dampers are analyzed and judged by the controller and command the power source to supply voltage to MR dampers, and control forces produced by MR dampers are applied to the structure to reduce its responses. With the development of the computing capacity of computers, the finite element method has become one of the most important research approaches in the engineering fields. To conduct a nonlinear seismic damage analysis of semiactive control system in general finite element software, the transducers, the semiactive controller, and the actuators should be developed into the subroutines, and unobstructed contact with the main program besides has the advantages of fast computation, numerical stable and high precise.

The frame of the developed semiactive control platform is shown in Figure 1. The finite element model of the structure is built through the preprocessor of the main program, in which the material models, element types, contact definition, boundary conditions, and load conditions are all reasonably defined. The subroutines are called step by step during the simulation, where the Bouc-Wen model [11] is used to portray the behavior of MR dampers. Both the main program and the subroutines of LS-DYNA software are based on explicit integration method in which the mass and stiffness matrices are uncoupled; therefore, the active control strategy based semiactive control method is unsuitable for this control platform. What is more, the practical structures experience degenerated performance during strong earthquakes, and the controller designed by the initial stiffness matrix may lead the control process to be unstable and divergent, so the simple bang-bang control law is employed in this platform as follows:

$$
F(t)= \begin{cases}F_{I, \max } & x \dot{x}>0 \\ F_{I, \min } & x \dot{x} \leq 0\end{cases}
$$

where $F(t)$ is the control force produced by MR damper at time $t, F_{I, \max }$ and $F_{I, \text { min }}$ are the maximum and minimum control forces that MR dampers can produce at this moment.

\subsection{Nonlinear Damage Criteria}

2.2.1. Steel Damage Model. To accurately describe the accumulation and development of structural damage under strong earthquakes, a fiber beam element model approach based on a continuity damage mechanics material model proposed by Bonora [12] was developed in this paper. Each structural member is discretized into a number of sections, and each section is further divided into a number of fibers, as shown in Figure 2. The sections are located either at the center of the element or at its Gaussian integration points, so that the behavior of each fiber is tracked using a simple uniaxial material model allowing an easy and efficient implementation of the inelastic performance, such as the strength and stiffness degradation behavior. In the continuity damage mechanics based steel material model, the plastic potential $f_{p}$ is defined as follows:

$$
f_{p}=\sigma_{\text {eq }}-k(\kappa)-\frac{3}{4 \alpha_{\infty}} \alpha_{i j}^{\prime} \alpha_{i j}^{\prime}-\sigma_{y},
$$

where $\sigma_{y}$ is the initial uniaxial yield stress, $\alpha_{\infty}$ is kinematic hardening saturation value, and $\sigma_{\mathrm{eq}}$ is the equivalent stress and is given by

$$
\sigma_{\text {eq }}=\left[\frac{3}{2}\left(\frac{s_{i j}}{1-d}-\alpha_{i j}^{\prime}\right)\left(\frac{s_{i j}}{1-d}-\alpha_{i j}^{\prime}\right)\right]^{1 / 2},
$$

where $s_{i j}$ and $\alpha_{i j}^{\prime}$ are the deviatoric parts of the stress and kinematic hardening tensor, respectively. $k$ is the isotropic hardening stress and is defined through Osgood equation:

$$
k(\kappa)=\frac{E_{h}}{\beta}[1-\exp (-\beta \kappa)],
$$

where $E_{h}$ is the isotropic hardening modulus, $\beta$ is isotropic hardening parameter, in which set $\beta=0$ for linear isotropic hardening, and $\kappa$ is the isotropic hardening coefficient and is defined as the equivalent accumulated plastic strain:

$$
\kappa=\varepsilon_{p}=\int d \varepsilon_{p} .
$$

The plastic strain components and the internal variables associated with $k$ and $\alpha_{i j}^{\prime}$ can be derived from $f_{p}$ by the normality rule:

$$
\begin{gathered}
d \varepsilon_{i j}^{p}=d \lambda \frac{\partial f_{p}}{\partial \sigma_{i j}}=\frac{3}{2} \frac{d \lambda}{1-d} \frac{\left(s_{i j} /(1-d)\right)-\alpha_{i j}^{\prime}}{\sigma_{\mathrm{eq}}} \\
d \alpha_{i j}^{\prime}=C(1-d) d \varepsilon_{i j}^{p}-\frac{3 C}{2 \alpha_{\infty}} \alpha_{i j}^{\prime} d \lambda \\
d \kappa=-d \lambda \frac{\partial f_{p}}{\partial k}=d \lambda=(1-d) d \varepsilon_{p},
\end{gathered}
$$

where $C$ is the kinematic hardening modulus, $\lambda$ is the plastic multiplier, and

$$
d \varepsilon_{p}=\left(\frac{2}{3} d \varepsilon_{i j}^{p} d \varepsilon_{i j}^{p}\right)^{1 / 2} .
$$

The damage dissipation potential is expressed as

$$
f_{d}=\left[\frac{1}{2}\left(-\frac{Y}{S_{0}}\right)^{2} \frac{S_{0}}{1-d}\right] \frac{\left(d_{\mathrm{cr}}-d\right)^{1-1 / v}}{\kappa^{(2+n) / n}} .
$$

The kinetic law of damage evolution is given by

$$
\dot{d}=-d \lambda \frac{\partial f_{d}}{\partial Y}=\frac{\left(d_{\mathrm{cr}}-d_{0}\right)^{1 / v}}{\ln \left(\varepsilon_{u}-\varepsilon_{\mathrm{th}}\right)} f\left(\frac{\sigma_{m}}{\sigma_{\mathrm{eq}}}\right)\left(d_{\mathrm{cr}}-d\right)^{1-1 / v} \frac{d \kappa}{\kappa}
$$

where $Y$ is the variable associated with damage, $v$ and $S_{0}$ are the material parameters, $\varepsilon_{u}$ and $\varepsilon_{\text {th }}$ are the critical and threshold equivalent accumulated plastic strains, and $d_{\mathrm{cr}}$ and $d_{0}$ are critical and initial damages of the material corresponding to $\varepsilon_{u}$ and $\varepsilon_{\text {th }}$, respectively. 


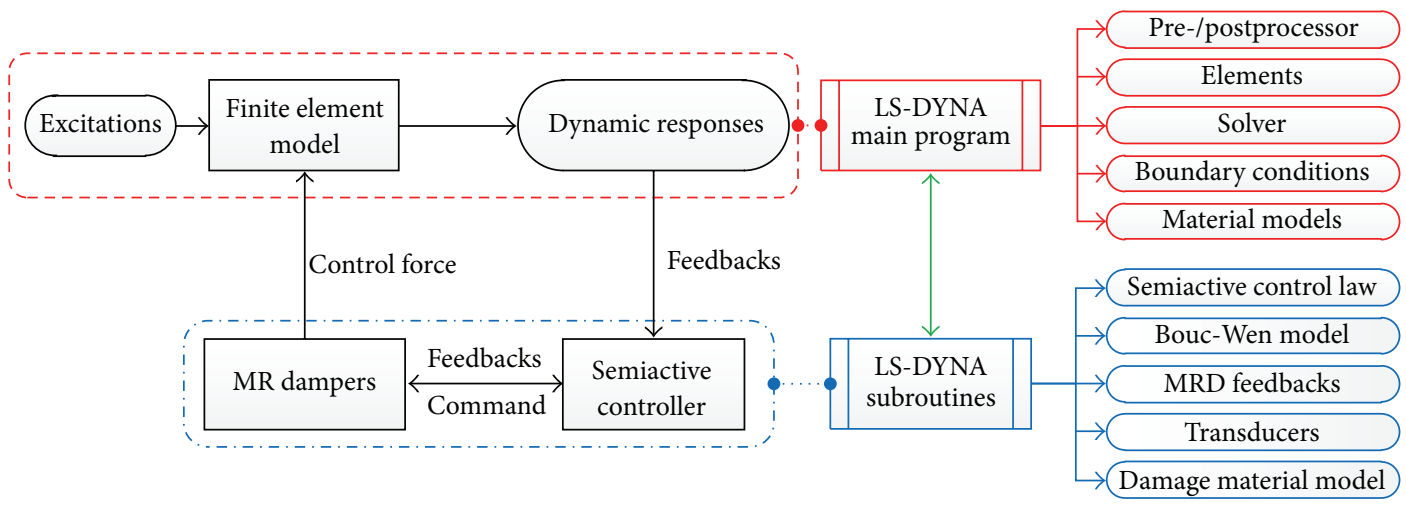

FIgURE 1: The frame of semiactive control platform in LS-DYNA program.

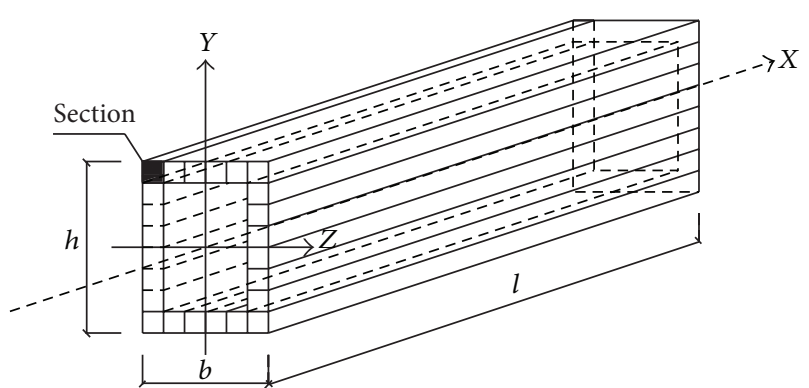

Figure 2: The discretization of structural members.

2.2.2. Shear Wall Damage Criteria. The pushover tests indicate that the well seismic designed shear wall will experience several stress states, that is, the elastic cracking of the concrete, yielding and reinforcing of the steel bars; the plastic flow of the steel bar, and crushing of concrete or rupture of the steel bars, the corresponding damage process of the shear wall can be divided into the elastic stage from the cracking of the concrete to the yielding of the steel bars, the stable stage, and the decrease stage. Here, the exponential and logarithmic composite function of Bonora model is used to simulate the damage process of the shear wall; the damage criteria is expressed as,

$$
d_{c}=d_{c, 0}+\left(d_{c, \mathrm{cr}}-d_{c, 0}\right)\left\{1-\left[1-\frac{\ln \left(\delta_{m} / \delta_{\mathrm{cra}}\right)}{\ln \left(\delta_{u} / \delta_{\mathrm{cra}}\right)}\right]^{\alpha_{c}}\right\},
$$

where the subscript $c$ denotes the concrete structure. $\delta_{m}$, $\delta_{u}$, and $\delta_{\text {cra }}$ are the maximum, ultimate, and cracking deformation of the shear wall member, respectively, and the other parameters are the same as in the Bonora model. For different $\alpha_{c}$ value, the model can simulate three typical damage progresses, as shown in Figure 3. Type 1 can simulate the ductile components such as the steel plate shear wall, in which the strength has a little decrease after the yielding of the member; type 3 can simulate the brittle components, in which the concrete crushes or the steel bar ruptures before the yielding of the member; and type 2 is the combination of the former two types, which has an obvious yield platform and is suitable to simulate the normal reinforced concrete shear wall member.

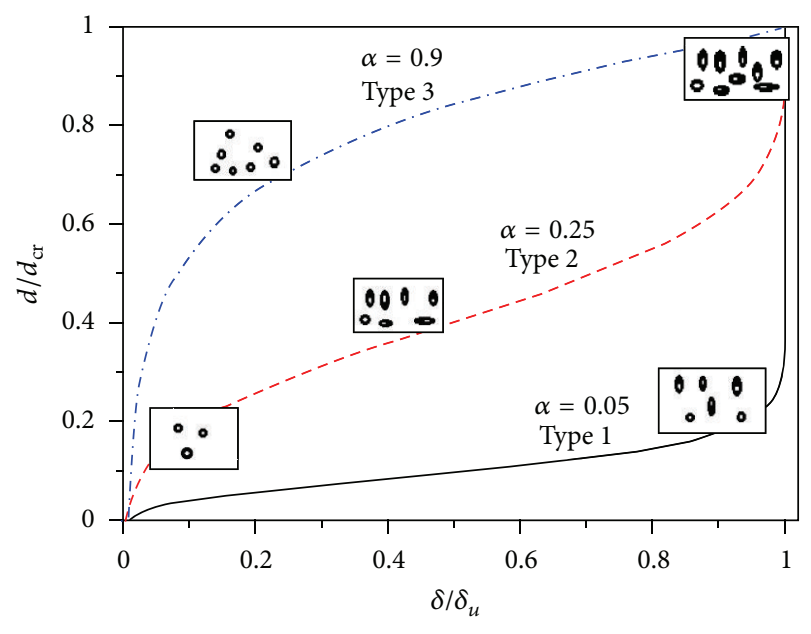

FIGURE 3: Three typical damage processes.

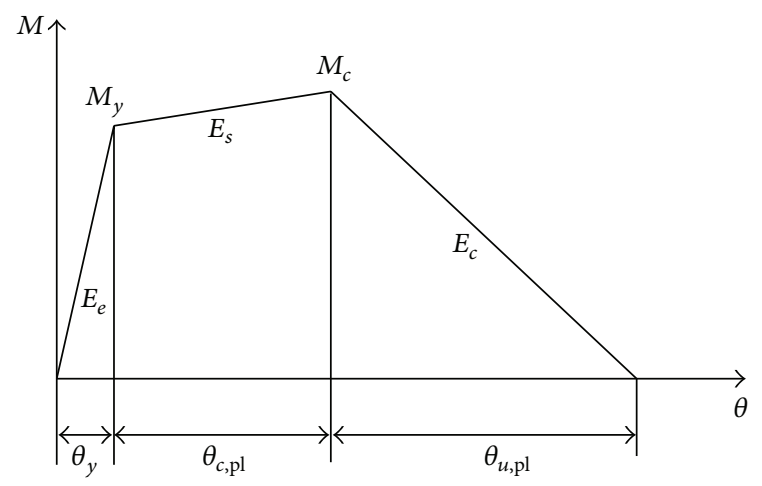

FIGURE 4: Lumped plastic hinge model.

Panagiotakos and Fardis [13] proposed a skeleton curve model of the reinforced concrete member by fitting a large number of tests data. As shown in Figure 4, the model uses 3 lines and 5 parameters, that is, $\theta_{y}, M_{y}, M_{c}, \theta_{c, \mathrm{pl}}$, and $\theta_{u, \mathrm{p} p}$, to simulate the yielding, reinforcing, and strength degeneration of the member, and the model is also suitable for the 
reinforced concrete shear wall members. The yield rotation and ultimate rotation are given by

$$
\begin{aligned}
\theta_{y}= & \phi_{y} \frac{L_{s}}{3}+0.0025+a_{\mathrm{sl}} \frac{0.25 \varepsilon_{y} d_{b} f_{y}}{\left(d-d^{\prime}\right) \sqrt{f_{c}^{\prime}}} \\
\theta_{u}(\%)= & \alpha_{\mathrm{st}} \alpha_{\mathrm{cyc}}\left(1+\frac{a_{\mathrm{sl}}}{2.3}\right)\left(1-\frac{a_{\mathrm{wall}}}{3}\right)\left(0.2^{\nu}\right) \\
& \times\left[\frac{\max \left(0.01, \rho^{\prime} f_{y}^{\prime} / f_{c}^{\prime}\right)}{\max \left(0.01, \rho f_{y} / f_{c}^{\prime}\right)} f_{c}^{\prime}\right]^{0.275} \\
& \times\left(\frac{L_{s}}{h}\right)^{0.45} 1.1^{\left(\alpha \rho_{s x}\left(f_{y h} / f_{c}^{\prime}\right)\right)}\left(1.3^{\rho_{d}}\right)
\end{aligned}
$$

where the parameters are the same as in [13]. The cracking rotation of the model is given by

$$
\theta_{\text {cra }}=\phi_{\text {cra }} \frac{L_{s}}{3}+0.0025+a_{\mathrm{sl}} \frac{0.25 \varepsilon_{y} d_{b} f_{y}}{\left(d-d^{\prime}\right) \sqrt{f_{c}^{\prime}}}
$$

where $\phi_{\text {cra }}$ is the curvature corresponding to the cracking of the member and calculated by the cracking strain of concrete. After getting the values of cracking rotation, yielding rotation and ultimate rotation, and assuming that the damage is 0 when the concrete cracks and the damage is 0.2 corresponding to the yielding of the steel bar [14], parameter $\alpha_{c}$ can be calculated by inversion solving (10) as

$$
\alpha_{c}=\log _{\zeta}^{0.8},
$$

where $\zeta$ is expressed as

$$
\zeta=1-\frac{\ln \left(\delta_{y} / \delta_{\text {cra }}\right)}{\ln \left(\delta_{u} / \delta_{\text {cra }}\right)} .
$$

\section{Numerical Example}

3.1. Simulation of Steel-Concrete Structure. The reinforced concrete tube, steel frame, slab, and connecting beam are the basic components of steel-concrete hybrid structure. In the finite element model, the steel frame is simulated by the fiber element model and the damage model developed in (9), the slab is simulated by the layered shell element model, the connecting beam is simulated by the lumped hinge plastic model [13], and the reinforced concrete tube is simulated by the layered shell element model and the damage model developed in (10). The concrete tube of the high-rise building structures usually experiences a global bending deformation due to earthquakes, which makes the upper stories of the concrete tube have a rigid body motion with the rotation of the lower stories, so the true relative deformation of the concrete tube should subtract the nonreal deformation. The relative displacement of the $i$ th story is calculated as follows:

$$
\Delta \delta_{i}=\Delta_{i}-\Delta_{i-1}-\theta H,
$$

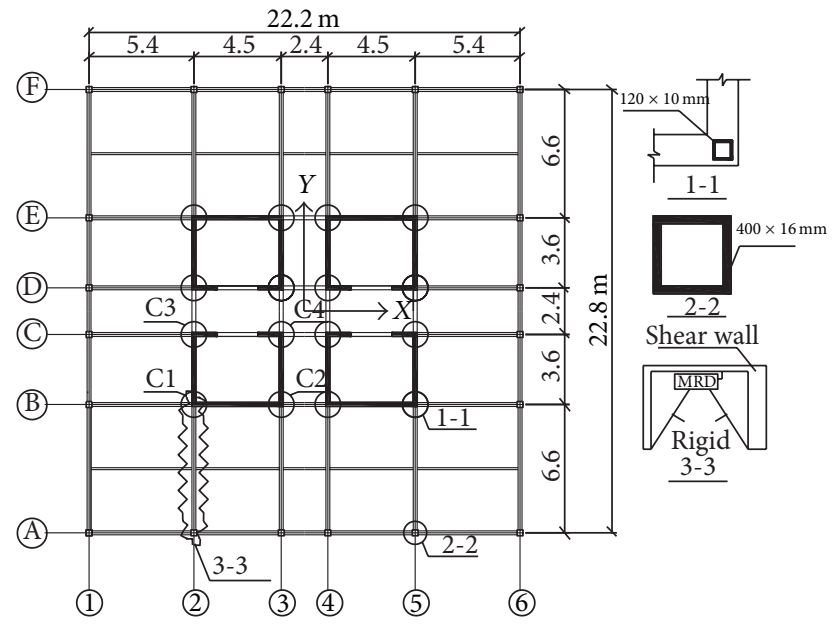

Figure 5: Plan view of the structure.

where $\Delta_{i-1}$ and $\Delta_{i}$ are the displacements of the $i$ th and $(i-1)$ th story, respectively, $\theta$ is the rigid rotation of the $(i-1)$ th story, and $H$ is the height of the $i$ th story.

The numerical example is a 15-story steel-concrete structure [15], as shown in Figure 5, which is $22.2 \mathrm{~m}$ by $22.8 \mathrm{~m}$ in plan with five bays each in the N-S $(X)$ and E-W $(Y)$ directions. The height of the structure is $58.5 \mathrm{~m}$ in elevation with each story height being of $3.9 \mathrm{~m}$. The shear wall depth of the 1st to 3rd story is $300 \mathrm{~mm}$, the 4th to 6th is $250 \mathrm{~mm}$, the 7th to 9th is $220 \mathrm{~mm}$, and that of other stories is $200 \mathrm{~mm}$. The sections of each type of structure members are the same, the columns are $\square 400 \times 400 \times 30$ hollow square steel tube, the beams are $\mathrm{H} 400 \times 250 \times 10 \times 16$ steel, the secondary beams are $\mathrm{H} 350 \times 200 \times 10 \times 12$ steel, and the connecting beams are $700 \times 250$ concrete. To increase the deformation capacity of the concrete tube, a box steel column is embedded at the intersection of the shear walls, the materials of the structure are C40 concrete, HRB335 steel bars, and Q345 steel for the steel frame, and the reinforcement ratio of the shear wall is 0.02 . Table 1 shows the parameters of the steel damage model.

MR dampers can significantly increase the energy dissipation capacity of the main structure and usually have little influence on the structural characters. For the determined structure, the internal energy dissipation capacity is controlled by the output force capacity of MR dampers, and the control force of MR damper at each story is optimized as follows:

$$
F_{j}=\frac{\xi_{j} D_{j} E_{j}}{\xi_{r} D_{r} E_{r}} F_{r}
$$

where $D_{r}, F_{r}, E_{r}$, and $\xi_{r}$ are the damage index, control force, dissipated energy, and normalized stiffness of the reference story, respectively. $D_{j}, F_{j}, E_{j}$, and $\xi_{j}$ are the damage index, control force, dissipated energy, and normalized stiffness of the $j$ th story, respectively. $F_{r}$ is determined by the expected control effectiveness and the design standard of MR damper, $\xi_{j}$ is the stiffness ratio of the $j$ th story to the sum of all the stories, and the damage index $D_{j}$ is the maximum damage value both in the $X$ and $Y$ direction of the concrete tube at the $j$ th story. 


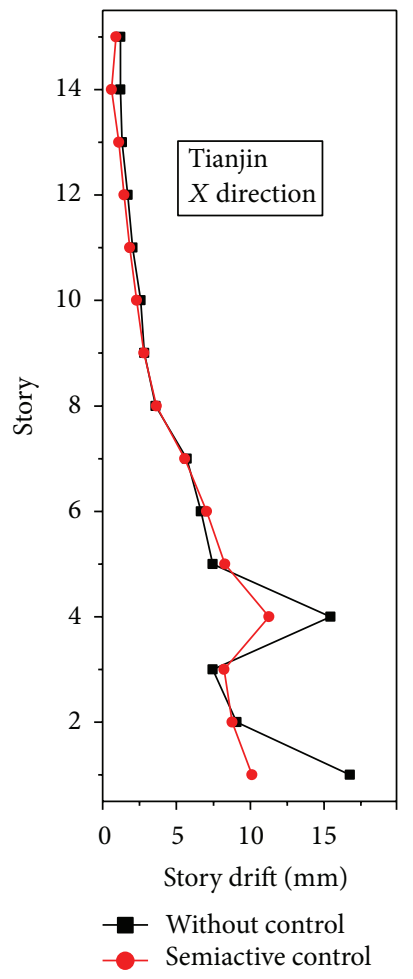

(a)

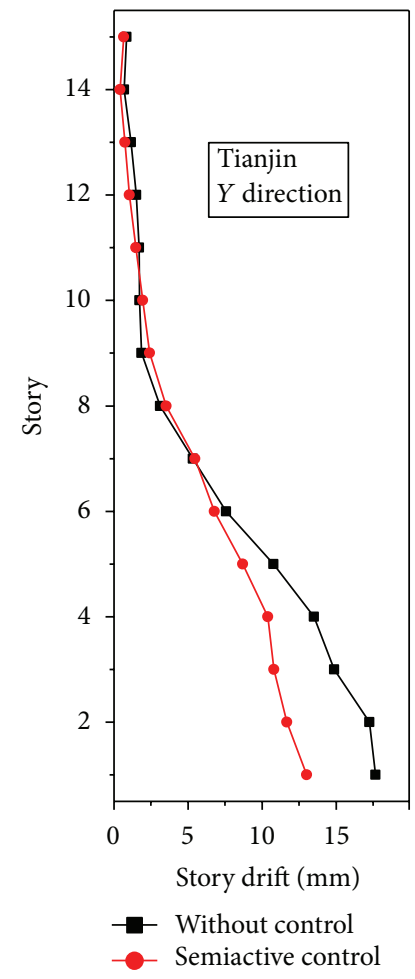

(b)

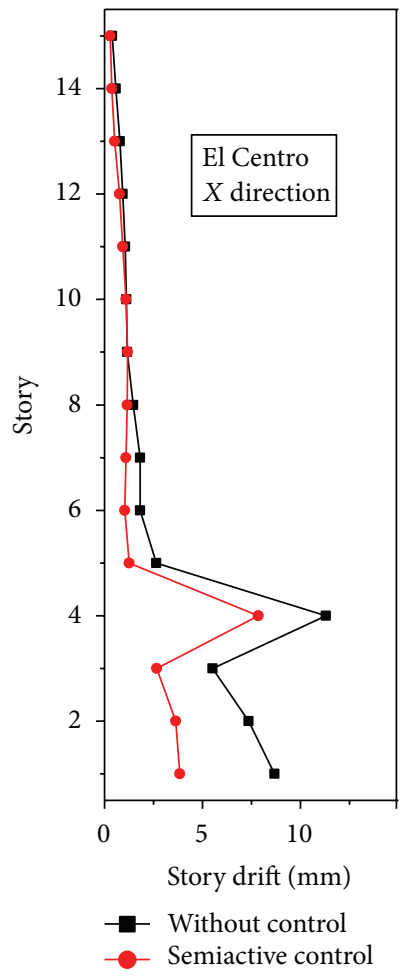

(c)

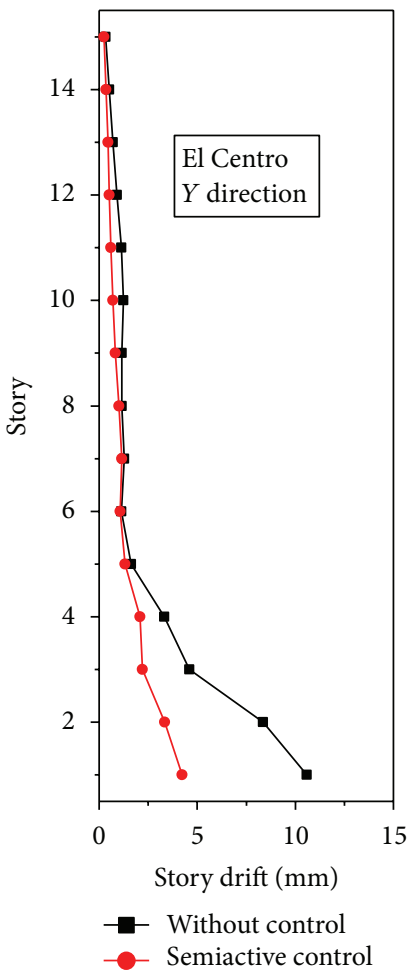

(d)

Figure 6: Envelope curve of story drift due to Tianjin and El Centro earthquakes in the $X$ and $Y$ directions.

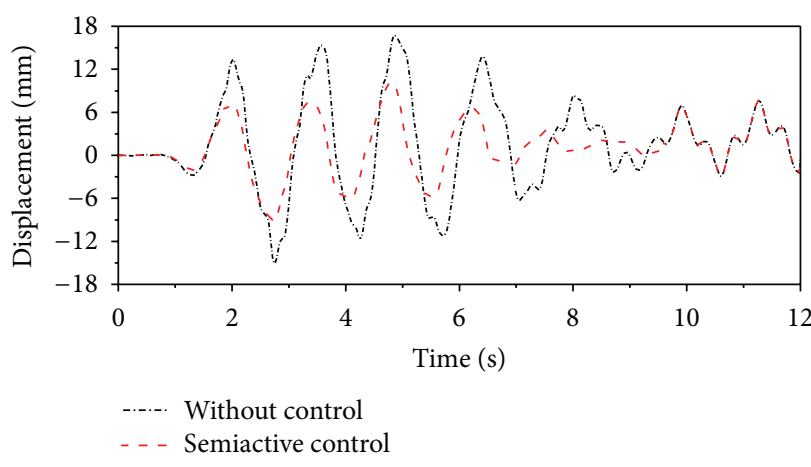

(a)

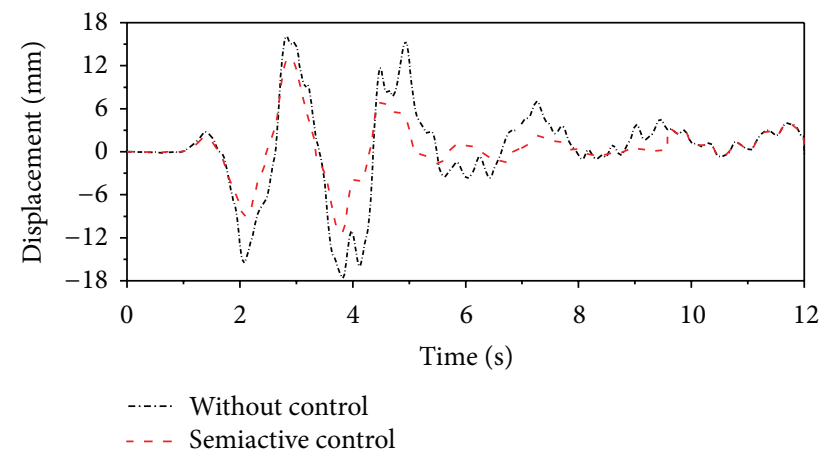

(b)

Figure 7: Displacement time history of the first floor due to Tianjin earthquake: (a) $X$ direction, (b) $Y$ direction.

TABLE 1: Material parameters.

\begin{tabular}{lccccccccc}
\hline \multirow{2}{*}{ Parameters } & \multicolumn{4}{c}{ Damage parameters } & \multicolumn{4}{c}{ Plastic parameters } \\
& $\varepsilon_{\text {th }}$ & $\varepsilon_{\text {cr }}$ & $D_{\text {cr }}$ & $D_{0}$ & $\alpha$ & $E_{h}[\mathrm{MPa}]$ & $\alpha_{\infty}[\mathrm{MPa}]$ & $C[\mathrm{MPa}]$ & $\beta$ \\
\hline Value & 0.001 & 0.24 & 0.065 & 0 & 0.2173 & 200 & 300 & 800 \\
\hline
\end{tabular}

TABLE 2: Control force of the MR dampers at each story.

\begin{tabular}{lccccccccc}
\hline Story & 1 & 2 & 3 & 4 & 5 & 6 & 7 & 8 & $9-15$ \\
\hline Damage & 0.420 & 0.404 & 0.358 & 0.395 & 0.272 & 0.193 & 0.152 & 0.110 & 0.061 \\
Energy/kJ & 69814 & 56353 & 43668 & 37305 & 34976 & 32268 & 29271 & 26593 & 21296 \\
Control force/kN & 1000 & 793 & 545 & 430 & 332 & 217 & 129 & 49 & 0 \\
\hline
\end{tabular}




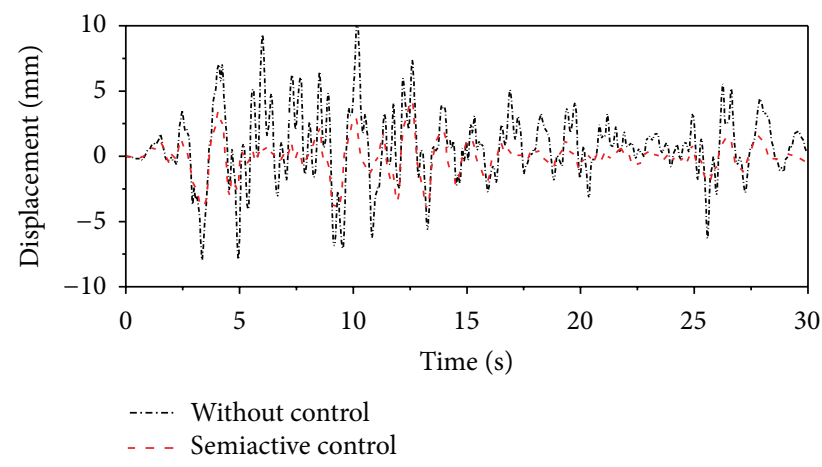

(a)

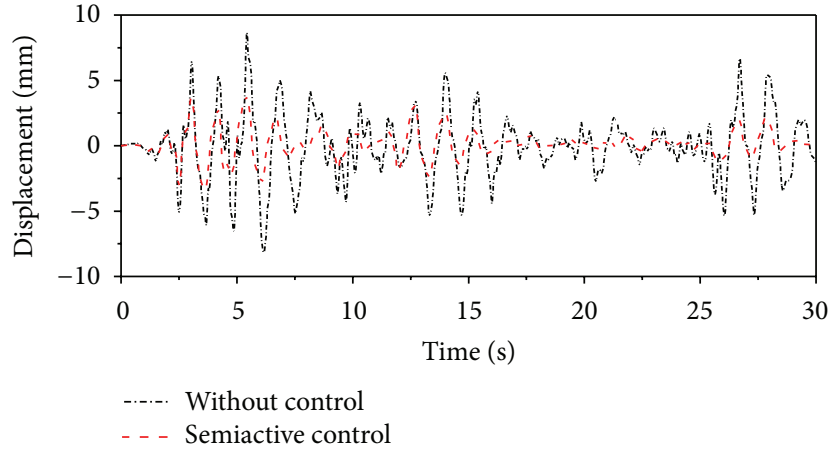

(b)

Figure 8: Displacement time history of the first floor due to El Centro earthquake: (a) $X$ direction, (b) $Y$ direction.

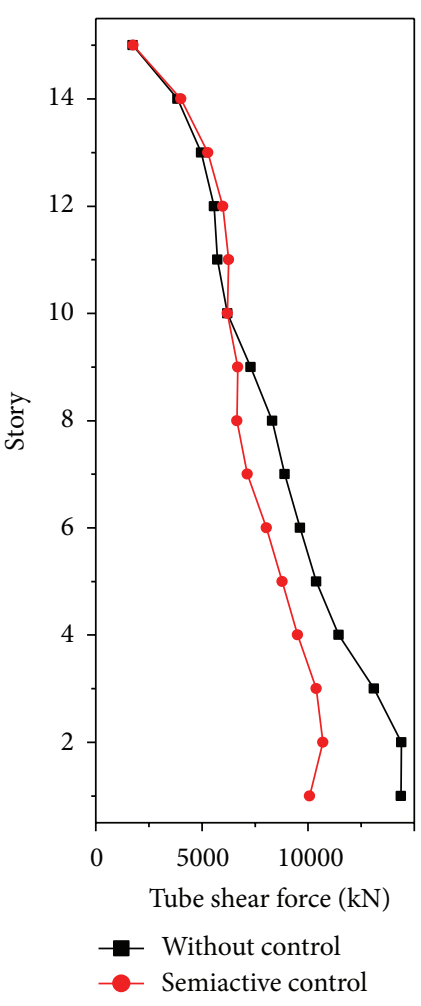

(a)
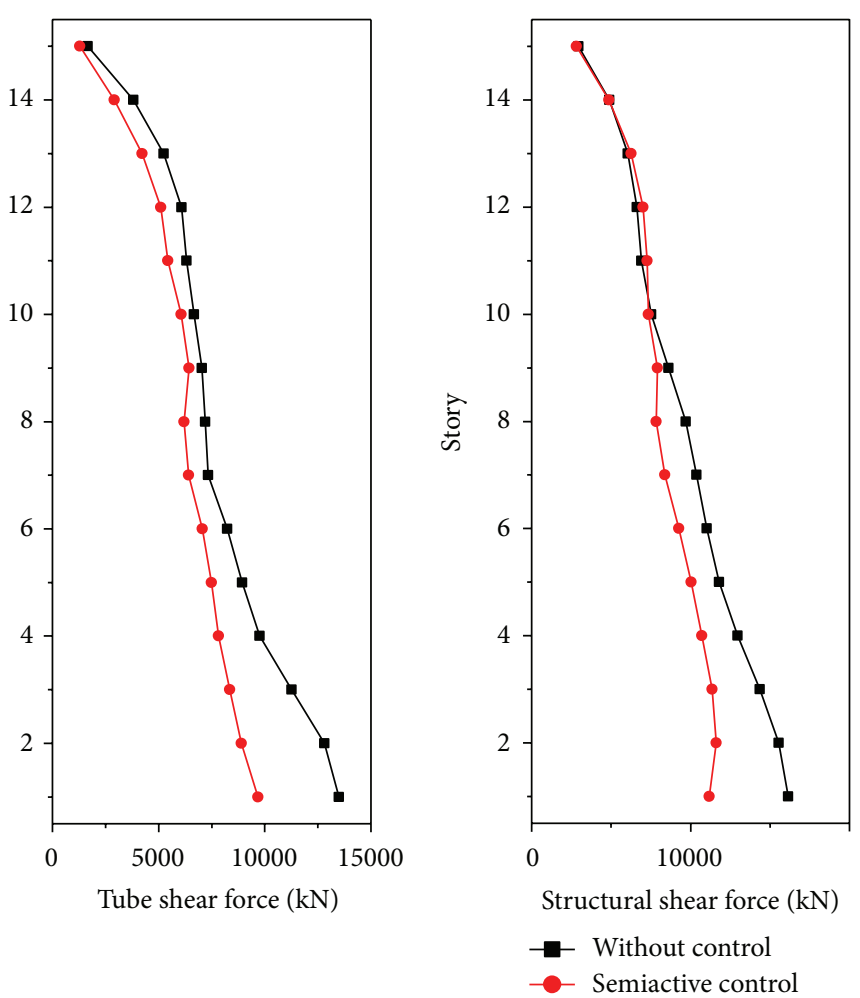

(b)

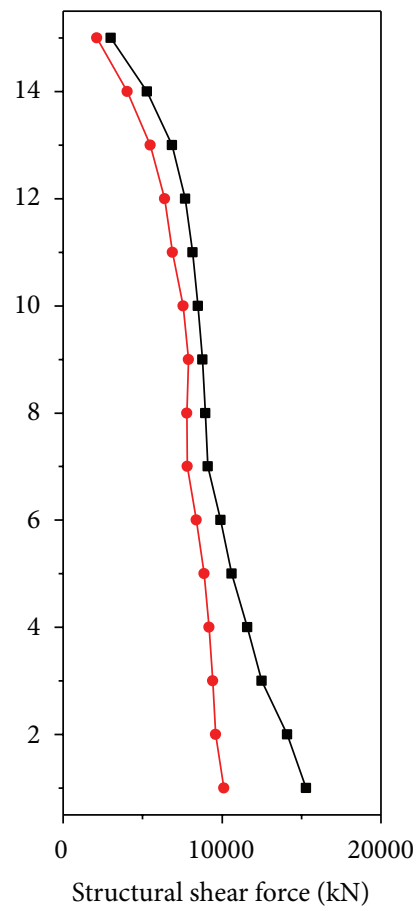

FIGURE 9: Shear force envelop curve of (a) concrete tube and (b) global structure in the $X$ and $Y$ directions.

Two directions of Tianjin, El Centro and Loma Prieta earthquake records with PGA of $0.3 \mathrm{~g}$ are used as the excitations. $16 \mathrm{MR}$ dampers are located between the steel frame and concrete tube from axis 2 to axis 5 and axis $B$ to axis $\mathrm{E}$ at each story, and a total of $128 \mathrm{MR}$ dampers are used from the 1st to 8th story, as shown in Figure 5. The damage process of the concrete tube, the internal energy of each story, and the optimized control force of MR dampers at each story is listed in Table 2.

3.2. Dynamic Responses Analysis. The dynamic responses of the steel-concrete structure with optimal designed force of MR dampers and without MR dampers are analyzed due to the PGA of $0.3 \mathrm{~g}$ Tianjin, El Centro and Loma Prieta earthquakes. The story drift envelop curve due to Tianjin and El Centro earthquakes is shown in Figure 6, and the relative displacement time histories of the first story are shown in Figures 7 and 8. It is indicated that the displacement of the controlled structure is smaller than that of the uncontrolled ones both in $X$ and $Y$ directions, the story drifts of the hybrid structure have been reduced by MR dampers and especially for the lower several stories because more powerful MR dampers are installed at the lower stories compared to the upper ones and the deformations are better controlled, while the members at upper several stories are still elastic and have very small deformation. From the envelop curves 


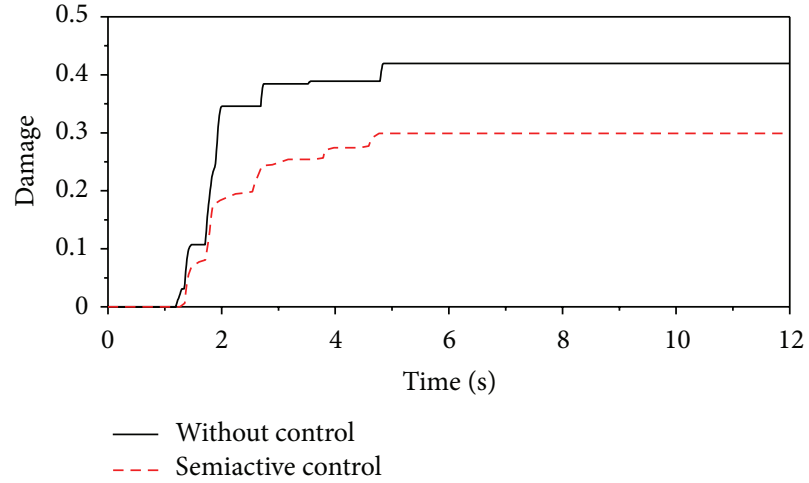

(a)

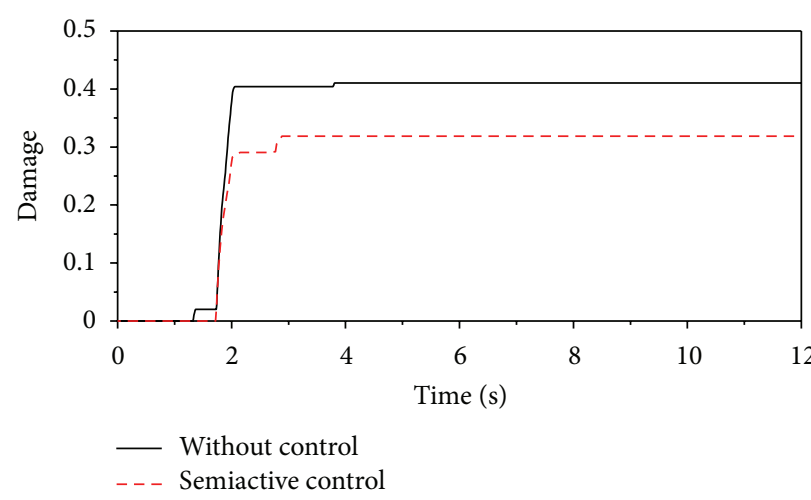

(b)

FIGURE 10: Damage process time history of the concrete core tube due to Tianjin earthquake: (a) $X$ direction and (b) $Y$ direction.

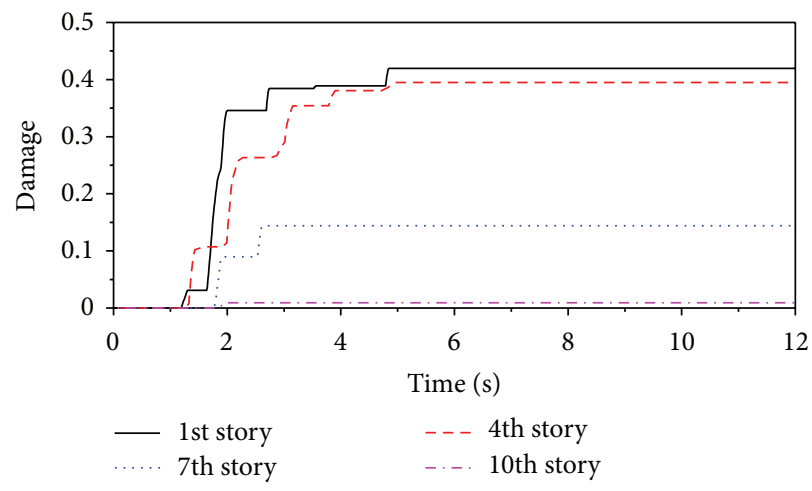

(a)

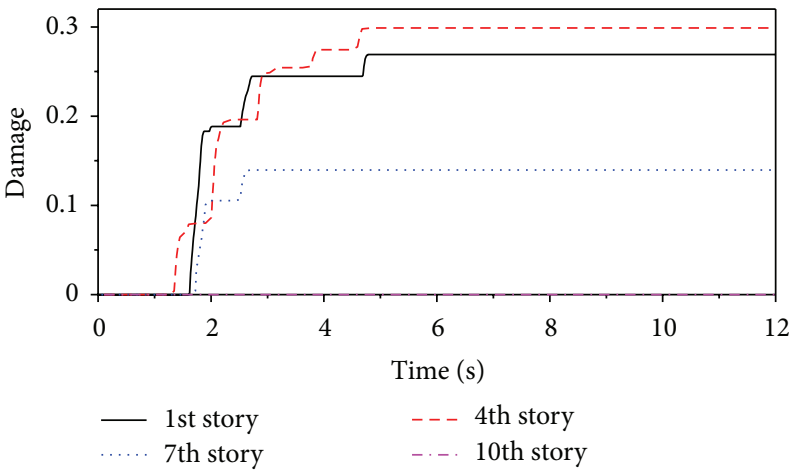

(b)

FIGURE 11: Damage process time history of the concrete core tube at some stories due to Tianjin earthquake: (a) without control and (b) semiactive control.

in the $X$ direction shown in Figure 6, the deformation drifts at the 4 th story because the depth of the shear wall changes here and the weak links occurr. For the controlled structure, the deformation is smaller but also drifts at the 4th story, so the MR dampers can reduce the structural deformation but cannot eliminate the weak links completely.

The shear force envelop curve of the concrete tube and the global structure due to El Centro earthquake are shown in Figure 9. It is shown that the shear force of the controlled structures is smaller than that of the uncontrolled ones, although the MR dampers are located at some lower stories, and the shear force of the upper stories is also well controlled, which demonstrates the excellent control performance of MR dampers for using in steel-concrete structures.

3.3. Damage Analysis. The damage process of the concrete tube and the steel columns of the hybrid structure due to Tianjin earthquake is analyzed based on the damage criteria of shear wall and the steel damage material model because there is no damage in the steel frame, and the damage analysis of the steel frame is not involved. The damage process of the structure with and without MR dampers is shown in Figure 10; it is indicated that the damage of the concrete tube of MR dampers controlled structure is much smaller than that of the uncontrolled ones because MR dampers are directly installed between the concrete tube and the steel frame; the deformations and shear forces of the tube and frame are better consorted by the control devices. Figure 10 also indicates that the damages of both the controlled and uncontrolled structures develop at the peak acceleration points and have the same process pattern; therefore, MR dampers can reduce the damage value but cannot eliminate the damage, which is consistent with the conclusions of the relative displacement, and it is also determined from the control mechanism of MR damper, that is, which can only apply the control force passively through the relative displacement of the story.

The damage process of the concrete tube at the stories where the shear wall depth changes, that is, the 1st, 4th, 7th, and 10th stories, is shown in Figure 11; it is indicated that the damage of the 10th story of MR dampers controlled structure is 0 , and the damage values of the other stories are also reduced. The controlled and uncontrolled structures have a similar damage process pattern, and the damage mainly shifts at the peak acceleration points. In addition, the damage process of the 4th story is fast because of the weak links.

The damage process of the embedded steel columns at the intersection of the concrete tube is shown in Figure 12, and the serial number of the columns is shown in Figure 5. It is 


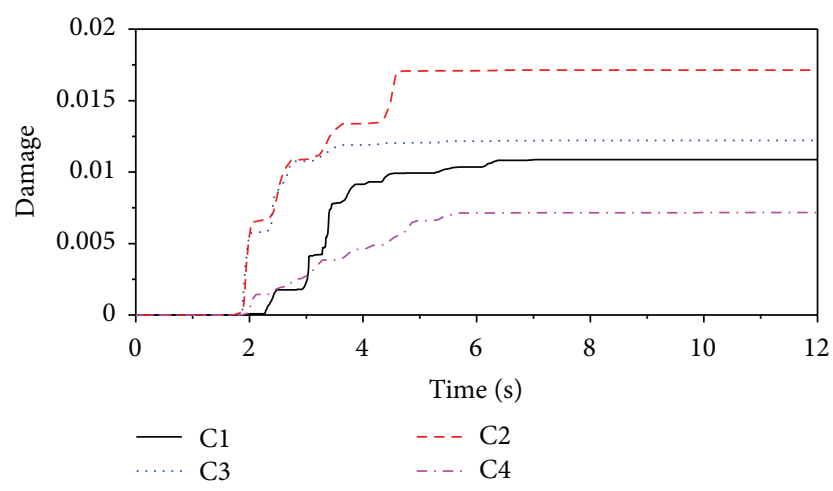

(a)

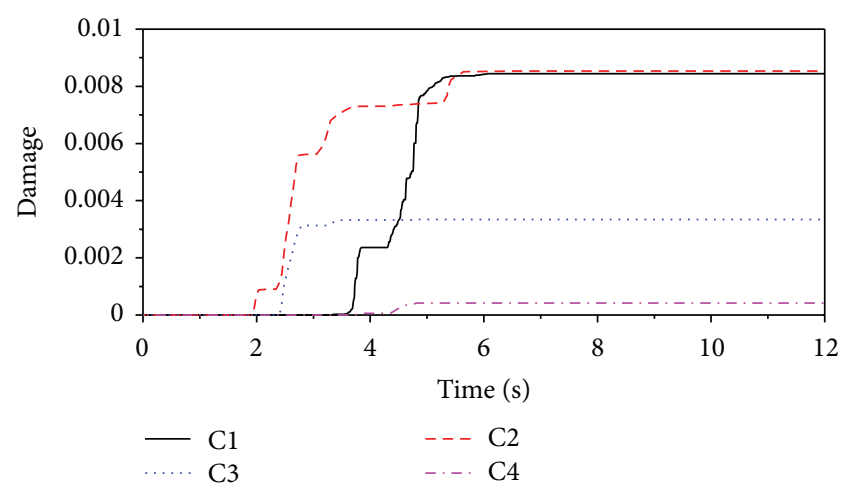

(b)

FIGURE 12: Damage process time history of each embedded steel column due to Tianjin earthquake: (a) without control and (b) semiactive control.

indicated that MR dampers can effectively reduce the damage intensity of the insert columns, and, comparing the damage processes of the concrete tube and the steel columns shows that the damage process of the steel columns lags behind the concrete tube and the steel columns also have obvious damage even after the peak acceleration points; the reason is that the concrete tube experiences serious damage at the peak acceleration points, and the degeneration of the concrete strength makes the steel columns sustain increasing shear force. And, for the lower several stories, the large bending moment causes the concrete tube to undertake large axial forces and crack under the tension forces, and then the axial forces are transferred to the steel columns; that is why the steel columns damage keeps increasing at the subsequent lower earthquakes. From the damage of different columns at the same story, it is indicated that the outside columns have larger damage than that of the inner columns, such as columns $\mathrm{C} 1, \mathrm{C} 2$, and $\mathrm{C} 3$ because the outside columns sustain bigger axial force to balance the bending moment of the structure. The damage process of structures with and without MR dampers is different; the reason is that the loading state of the embedded columns varies with the strength of the concrete tube, and the performance of the upper concrete tube and MR dampers will influence the loading state of the embedded columns and interfere with the damage process of the steel columns.

\section{Conclusions}

A semiactive control platform comprising the Bouc-Wen model of MR damper, the simple bang-bang semiactive control law, and the damage material model is developed in LS-DYNA program, based on the data transferring between the main program and the control platform; it can realize the purpose of integrated modeling, analysis, and design of the nonlinear semiactive control system. The steel damage model, damage criteria for the concrete shear wall, and the optimal designed control force of MR dampers are also developed. The nonlinear seismic control effectiveness is verified by the numerical example of a 15-story steel-concrete hybrid structure; results indicate that the control platform and the numerical method are stable and fast; the relative displacement, shear force, and damage of the steel-concrete structure are largely reduced using optimal designed MR dampers, when MR dampers are directly installed between the concrete tube and the steel frame; the deformations and shear forces of the concrete tube and frame are better consorted by the control devices. MR dampers also can effectively reduce the damage intensity of the embedded steel columns at the intersection of the concrete tube.

\section{Acknowledgments}

The authors gratefully acknowledge the partial support of this research by the National Natural Science Foundation of China under Grant no. 51178034 and the 111 project under Grant no. B13002.

\section{References}

[1] B. F. Spencer Jr. and S. Nagarajaiah, "State of the art of structural control," Journal of Structural Engineering, vol. 129, no. 7, pp. 845-856, 2003.

[2] Y. Ohtori, R. Christenson, B. F. Spencer Jr., and S. J. Dyke, "Benchmark control problems for seismically excited nonlinear buildings," Journal of Engineering Mechanics, vol. 130, no. 4, pp. 366-385, 2004.

[3] O. Yoshida and S. J. Dyke, "Seismic control of a nonlinear benchmark building using smart dampers," Journal of Engineering Mechanics, vol. 130, no. 4, pp. 386-392, 2004.

[4] N. Wongprasert and M. D. Symans, "Application of a genetic algorithm for optimal damper distribution within the nonlinear seismic benchmark building," Journal of Engineering Mechanics, vol. 130, no. 4, pp. 401-406, 2004.

[5] S. Sahasrabudhe and S. Nagarajaiah, "Experimental study of sliding base-isolated buildings with magnetorheological dampers in near-fault earthquakes," Journal of Structural Engineering, vol. 131, no. 7, pp. 1025-1034, 2005.

[6] S.-K. Lee, S.-H. Lee, K.-W. Min, B.-W. Moon, K.-J. Youn, and J.-S. Hwang, "Performance evaluation of an MR damper in building structures considering Soil-structure interaction 
effects," Structural Design of Tall and Special Buildings, vol. 18, no. 1, pp. 105-115, 2009.

[7] H. Li and J. Wang, "Experimental investigation of the seismic control of a nonlinear soil-structure system using MR dampers," Smart Materials and Structures, vol. 20, no. 8, Article ID 085026, 2011.

[8] J. E. Carrion, B. F. Spencer Jr., and B. M. Phillips, "Realtime hybrid simulation for structural control performance assessment," Earthquake Engineering and Engineering Vibration, vol. 8, no. 4, pp. 481-492, 2009.

[9] R. Christenson, Y. Z. Lin, A. Emmons, and B. Bass, "Large-scale experimental verification of semiactive control through realtime hybrid simulation," Journal of Structural Engineering, vol. 134, no. 4, pp. 522-534, 2008.

[10] E. Park, K.-W. Min, S.-K. Lee et al., "Real-time hybrid test on a semi-actively controlled building structure equipped with fullscale MR dampers," Journal of Intelligent Material Systems and Structures, vol. 21, no. 18, pp. 1831-1850, 2010.

[11] L. M. Jansen and S. J. Dyke, "Semiactive control strategies for MR dampers: comparative study," Journal of Engineering Mechanics, vol. 126, no. 8, pp. 795-803, 2000.

[12] N. Bonora, "A nonlinear CDM model for ductile failure," Engineering Fracture Mechanics, vol. 58, no. 1-2, pp. 11-28, 1997.

[13] T. B. Panagiotakos and M. N. Fardis, "Deformations of reinforced concrete members at yielding and ultimate," ACI Structural Journal, vol. 98, no. 2, pp. 135-148, 2001.

[14] M. S. Williams and R. G. Sexsmith, "Seismic damage indices for concrete structures: a state-of-the-art review," Earthquake Spectra, vol. 11, no. 2, pp. 319-349, 1995.

[15] Y. Zhou, X. L. Lu, Z. H. Huang, and Y. Bo, "Seismic behavior of composite shear walls with multi-embedded steel sections. Part II: analysis," The Structural Design of Tall and Special Buildings, vol. 19, no. 6, pp. 637-655, 2010. 


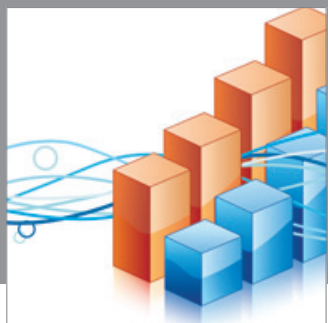

Advances in

Operations Research

mansans

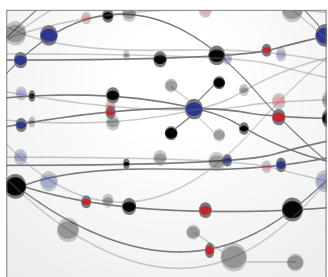

The Scientific World Journal
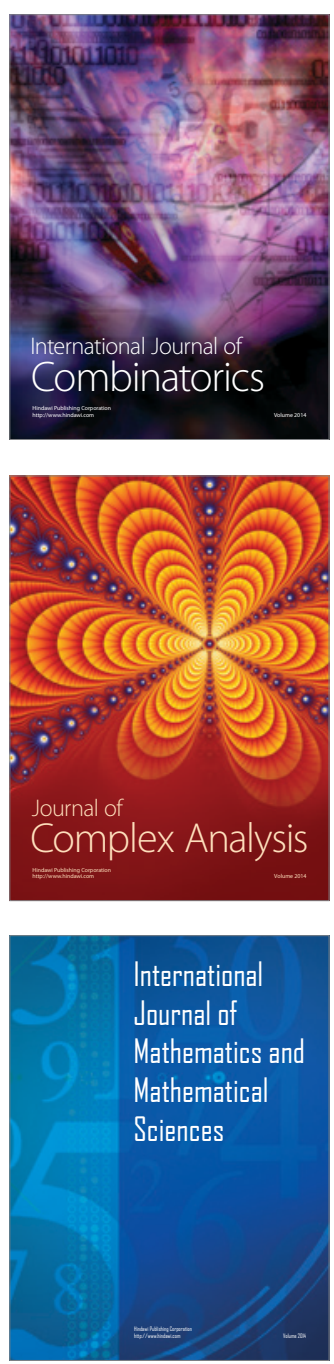
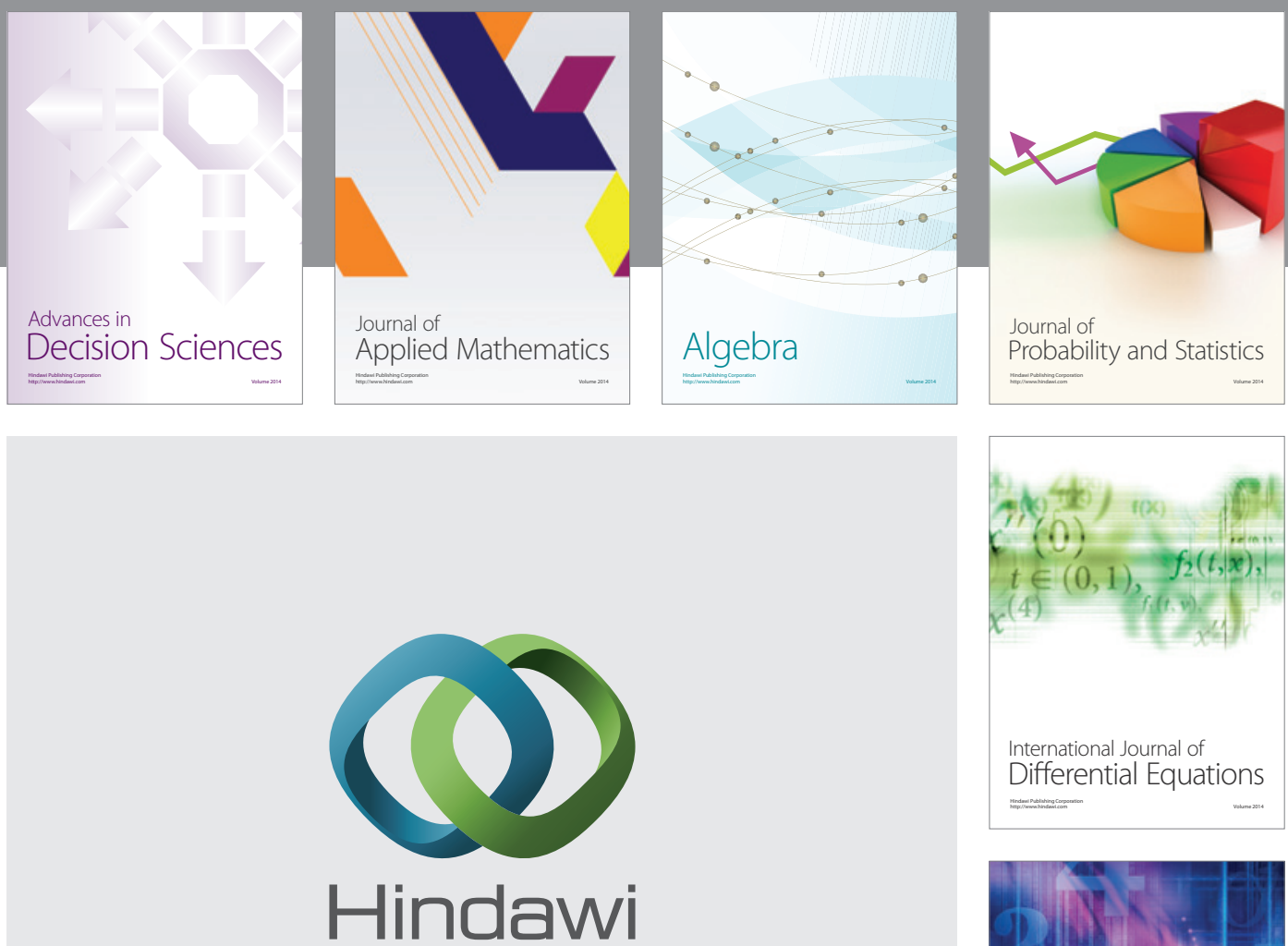

Submit your manuscripts at http://www.hindawi.com
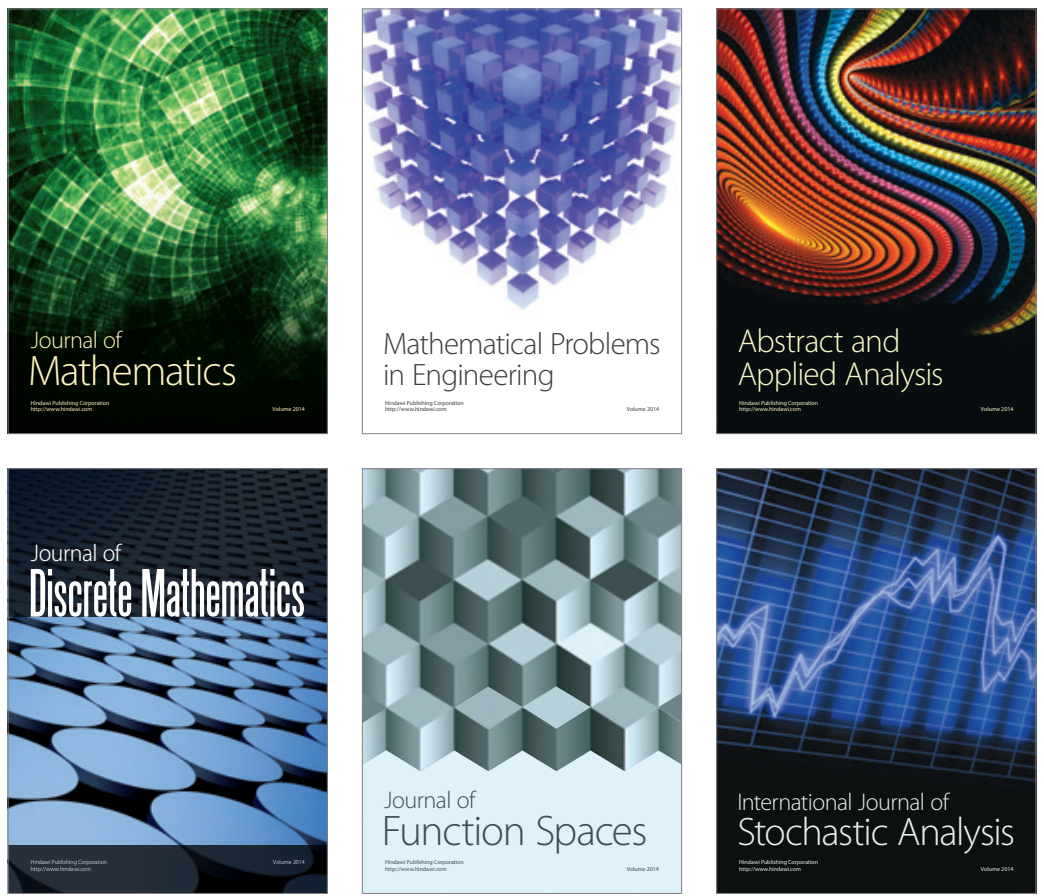

Journal of

Function Spaces

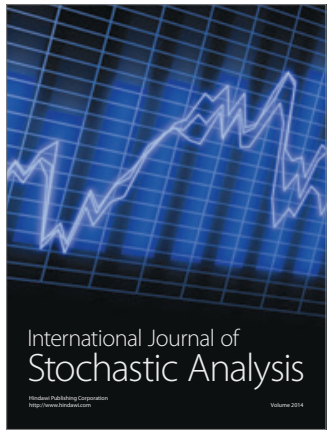

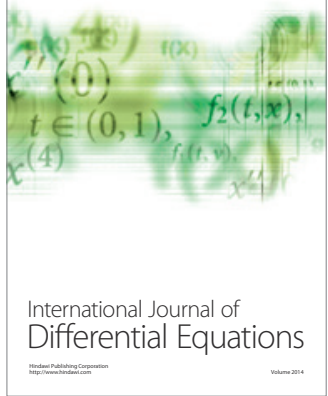
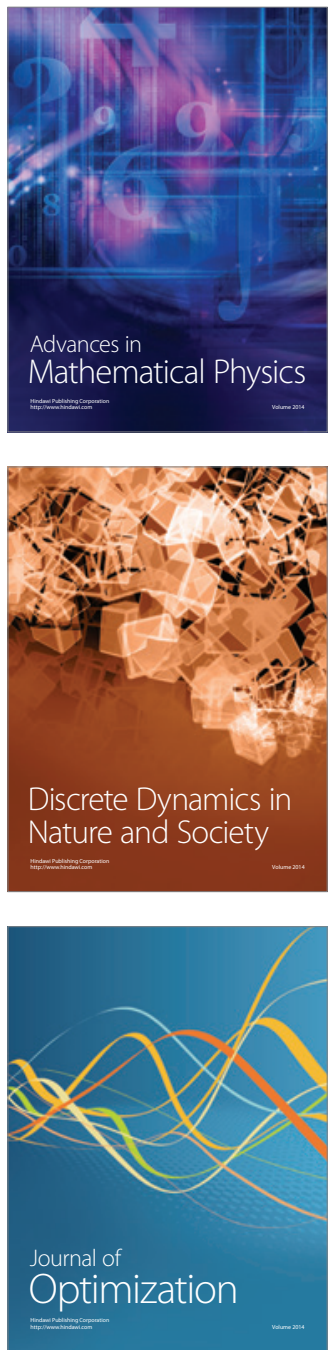